\title{
A Study on Competency Mapping in Manufacturing MSME Sector using Mathematical Model
}

\author{
P. Thamaraiselvi', D. Visagamoorthi' and A. Shobana ${ }^{2}$ \\ 'School of Management, Sri Krishna College of Engineering and Technology, \\ Kuniamuthur, Coimbatore - 641008, Tamil Nadu India; \\ thamaraiselvi@skcet.ac.in, visagamoorthi@skcet.ac.in \\ 2Department of Science and Humanities (Mathematics), Sri Krishna College of Engineering \\ and Technology, Kuniamuthur, Coimbatore - 641008, Tamil Nadu India; \\ shobanaa@skcet.ac.in
}

\begin{abstract}
Objectives: To analyze most and least possessed competencies and redefining the competencies using mathematical modeling with reference to Micro, Small and Medium Enterprises (MSME) in Coimbatore district, Tamil Nadu, India. Methods/Statistical Analysis: Data collected through structure questionnaire with five core competencies which were distributed to the employees of MSME in the Coimbatore district. Five point scales were used to assess both present and expected levels. The 100 samples from 50 MSME units based on their turnover for the past five years were drawn through random sampling technique. The data for the study were primary in nature and research design is descriptive design. Findings: Employees were normal and neutral in giving opinion to their respective leaders and the leadership qualities and creativity/ innovation skills. The overall mean score showcases that the employees are competent enough in taking their assigned job in their specialized area. The relationship between core competencies and experience remains to be positive in nature. Core competencies and grades of the employees do not have signitificants Communication, decision making and teamwork are most possessed and preferred core competencies and leadership and creativity/innovation are least possessed core competencies in the MSME sector. The senior grade employees possess the expected leadership and communication skills, which is one of the essential skills of the top management. The middle level managers in all the grades possess team building skills, information development skills. Through the gap analysis mathematical model it is proved that the expected skills can be mapped with the actual skills. This in turn enhances the management to make proper decisions in allocation of quality work to appropriate employee. Application/ Improvements: The study gives a scope to implement the work in other sectors and the proved gap analysis can be used to measure competencies actually owned and expected by management.
\end{abstract}

Keywords: Competency Mapping, Gap Analysis, Manufacturing Sector, Mathematical Model, Micro, Small and Medium Enterprises (MSME)

\section{Introduction}

Manufacturing industries contribute a lot to the Gross Domestic Product (GDP) of the nation. This sector is an important and essential sector which lay a platform for new improvements in all manufacturing process and products. There are few successful initiatives and programs which are launched to contribute to reorganization which directly contributes to economical growth.
India is expected to become a fifth largest manufacturing country by the year 2020 and we are in the race to achieve the target. Manufacturing sector has all the distinguished potential to reach USD \$1.5 trillion and we can positively witness the business development which is continuously moving in positive direction. By the year 2025 , from $16 \%$ the government will reach a target of $25 \%$ of GDP (report) ${ }^{1}$. In terms of number, the factories and industrial workers in Coimbatore district (selected place

*Author for correspondence 
of research) rank one among the best when compared to all other districts. It has a wide diversified range of manufacturing sector market when compared to other districts.

\section{Objectives}

- To study the competencies and redefining the competencies using mathematical modeling with reference to MSME in Coimbatore district,

- To study and assess the competency of the employees using mathematical modeling in the MSME sector of the district, and

- To find out the most and least possessed competencies of the employees using mathematical modeling in MSME of manufacturing industries in Coimbatore district.

\section{Methodology}

The expected competencies of employees are assessed through a well defined structure questionnaire with five core competencies which were administered and distributed to the defined employees of MSME of the manufacturing industries in the Coimbatore district ${ }^{2-4}$. The employees were instructed to assess and evaluate their existing levels and compare the same with their expected level with reference to competencies required for the specific jobs. Five point scales were used to assess both present and expected levels.

Descriptive research design was adopted for the research study in MSME sector. The samples were drawn through Random sampling technique. Samples of 100 employees from 50 MSME companies in the district were drawn as the sample for the research study. 50 companies from MSME sector were selected based on their turnover for the past five years. The data collected for the study were primary in nature.

Statistical Tools Used for analysis:

1. Percentage analysis,

2. Gap analysis - a defined mathematical model ${ }^{5-6}$,

3. Correlation ${ }^{7}$, and

4. One way ANOVA.

\section{Demographic Details}

Classification of employees based on their demographic details required for the study in Table 1.
Table 1. Demographic classification of employees

\begin{tabular}{|c|c|c|c|c|}
\hline $\begin{array}{l}\text { Sl. } \\
\text { No. }\end{array}$ & \begin{tabular}{|c|} 
Demographic \\
Details
\end{tabular} & Classification & Frequency & (\%) \\
\hline \multirow[t]{3}{*}{1.} & \multirow[t]{3}{*}{ Gender } & Male & 46 & 92.0 \\
\hline & & Female & 4 & 8.0 \\
\hline & & Total & 50 & 100 \\
\hline \multirow[t]{5}{*}{2.} & \multirow[t]{5}{*}{ Age } & $20-29$ & 7 & 14.0 \\
\hline & & $30-39$ & 21 & 42.0 \\
\hline & & $40-49$ & 12 & 24.0 \\
\hline & & $50-59$ & 10 & 20.0 \\
\hline & & Total & 50 & 100 \\
\hline \multirow[t]{3}{*}{3.} & \multirow[t]{3}{*}{ Marital Status } & Married & 45 & 90.0 \\
\hline & & Unmarried & 5 & 10.0 \\
\hline & & Total & 50 & 100 \\
\hline \multirow[t]{6}{*}{4.} & \multirow{6}{*}{$\begin{array}{l}\text { Educational } \\
\text { Qualification }\end{array}$} & SSLC/HSC & 2 & 4.0 \\
\hline & & Graduate & 23 & 46.0 \\
\hline & & Post-Graduate & 11 & 22.0 \\
\hline & & Professional & 3 & 6.0 \\
\hline & & Other & 11 & 22.0 \\
\hline & & Total & 50 & 100 \\
\hline \multirow[t]{4}{*}{5.} & \multirow{4}{*}{$\begin{array}{l}\text { Monthly } \\
\text { Income }\end{array}$} & Up to Rs. 25,000 & 13 & 26.0 \\
\hline & & Rs.25,001-Rs.50,000 & 34 & 68.0 \\
\hline & & Rs.50,001-Rs.75,000 & 3 & 6.0 \\
\hline & & Total & 50 & 100 \\
\hline \multirow[t]{8}{*}{6.} & \multirow[t]{8}{*}{ Grade } & SM (Senior Manager) & 3 & 6.0 \\
\hline & & M1(Manager) & 3 & 6.0 \\
\hline & & $\begin{array}{l}\text { M2 (Deputy } \\
\text { Manager) }\end{array}$ & 4 & 8.0 \\
\hline & & $\begin{array}{l}\text { M3 (Assistant } \\
\text { Manager) }\end{array}$ & 4 & 8.0 \\
\hline & & M4 (Junior Manager) & 9 & 18.0 \\
\hline & & O1 (Senior Officer) & 12 & 34.0 \\
\hline & & O2 (Junior Officer) & 10 & 20.0 \\
\hline & & Total & 50 & 100 \\
\hline \multirow[t]{5}{*}{7.} & \multirow[t]{5}{*}{ Experience } & $1-9$ & 12 & 24.0 \\
\hline & & 10-19 & 21 & 42.0 \\
\hline & & $20-29$ & 13 & 26.0 \\
\hline & & 30-39 & 4 & 8.0 \\
\hline & & Total & 50 & 100 \\
\hline
\end{tabular}

\section{Identifying Core Competencies}

Competencies and qualifications (with skills) to perform a job was well defined and different classifications were 
given to the employees in a structured manner. The Core competencies which were given higher consideration in this study are as follows: communication, leadership, creativity/innovation, decision-making, and teamwork skills.

\section{Gap Analysis}

Comparison of actual performance with the expected level of each competency is done thorough Gap analysis a defined mathematical model. Grade SM4 shown in Figure 1 Employees have good communication skill when compared to all other skills like decision making, creativity/innovation and leadership and teamwork skills. Grade M1 shown in Figure 2 posses the competencies expected and meet the expectation of team workers. They exhibit decision making skills whenever required. Employees were behind the expected level for creativity/innovation and leadership skills, and communication. Employees meet the expectation for communication, creativity and

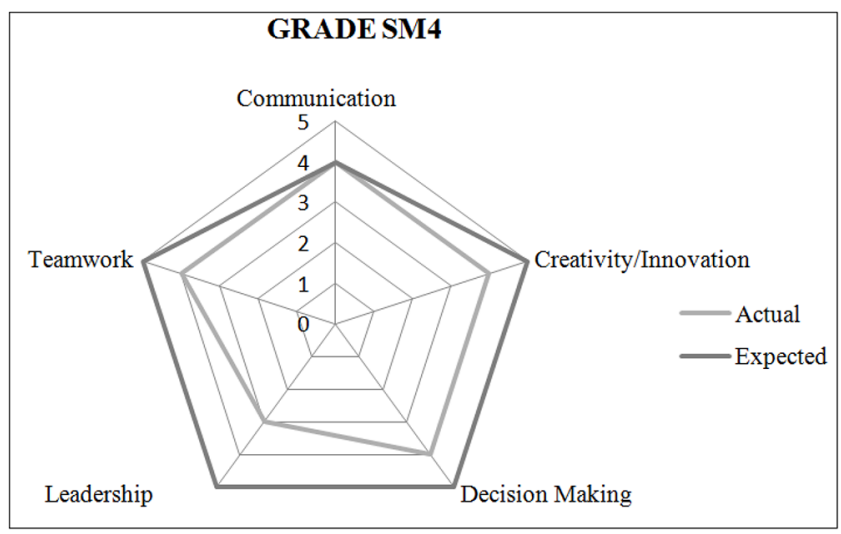

Figure 1. Gap analysis: Grade SM 4.

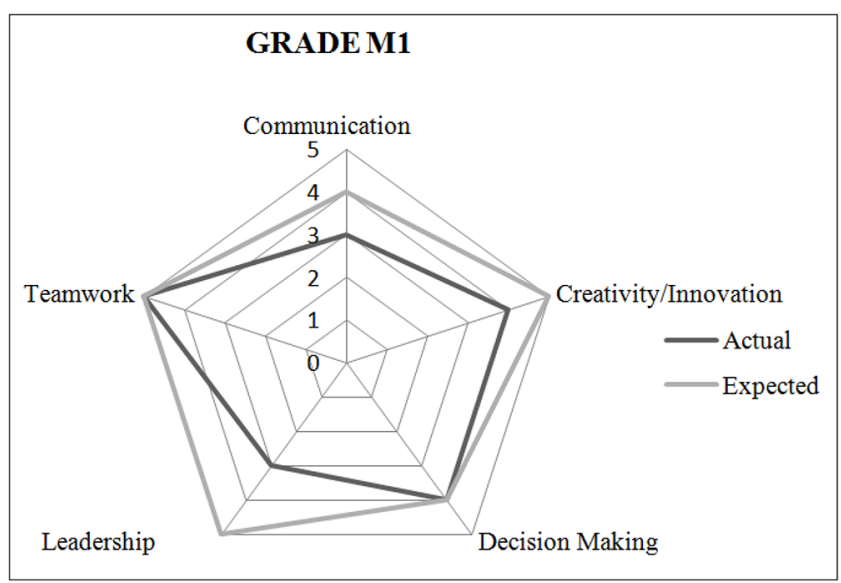

Figure 2. Gap analysis: Grade M1.

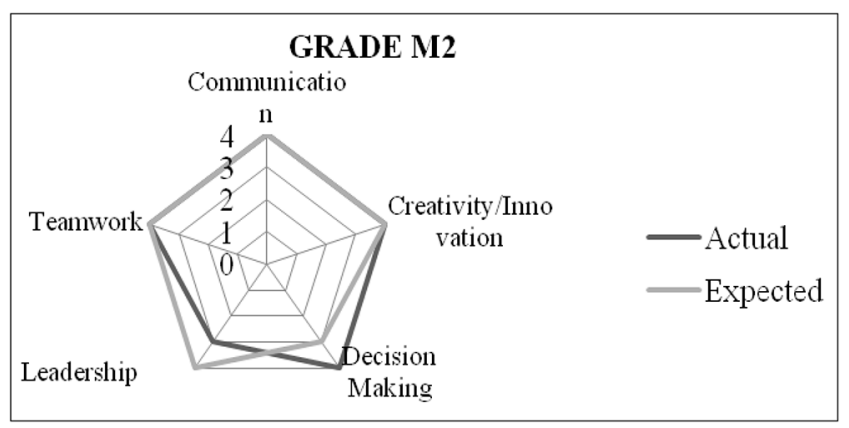

Figure 3. Gap analysis: Grade M2.

teamwork skills, which stand far behind the expected level for leadership skill and exceeded the expected level for decision making skill among Grade M2 (Figure 3).

Employees meet the expectation of teamwork and contribute for decision making with their skills and were behind the expected level in case of communication, creativity and leadership skills in Grade M3 (Figure 4). From the analysis it is interpreted that Grade M4 (Figure 5) meets the expectation for communication, creativity and leadership skills and exceeded the expected level for decision making and teamwork skills. It is analyzed that the employees meet the expectation of creativity/innovation and leadership skills, communication and exceeded

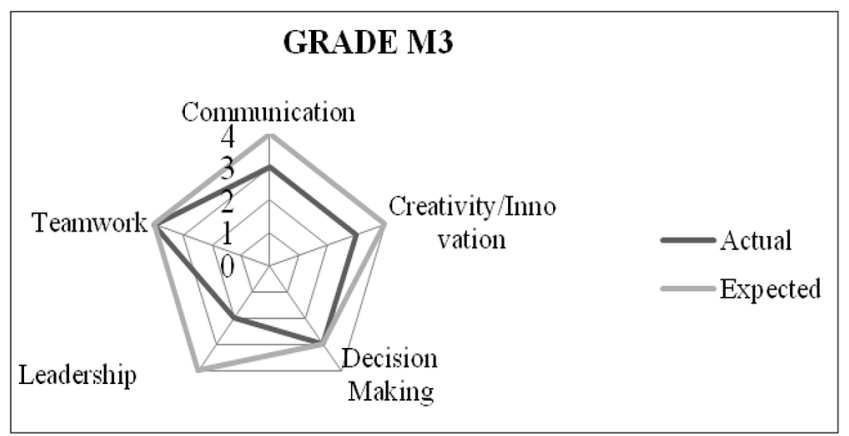

Figure 4. Gap analysis: Grade M3.

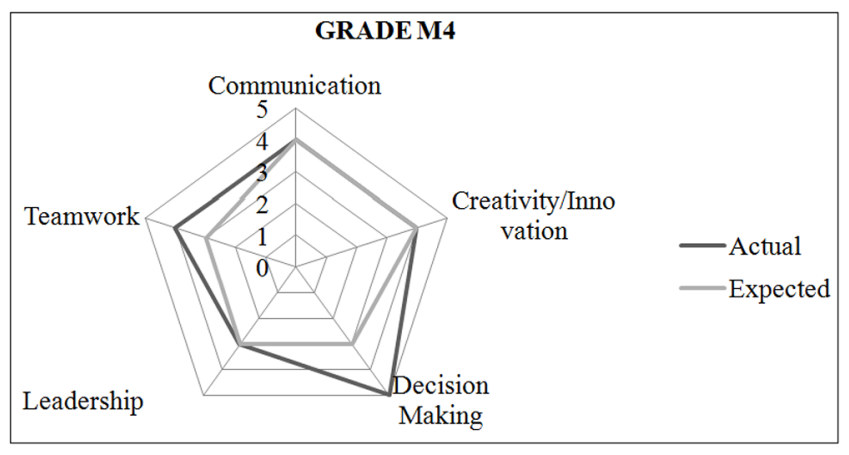

Figure 5. Gap analysis: Grade M4. 


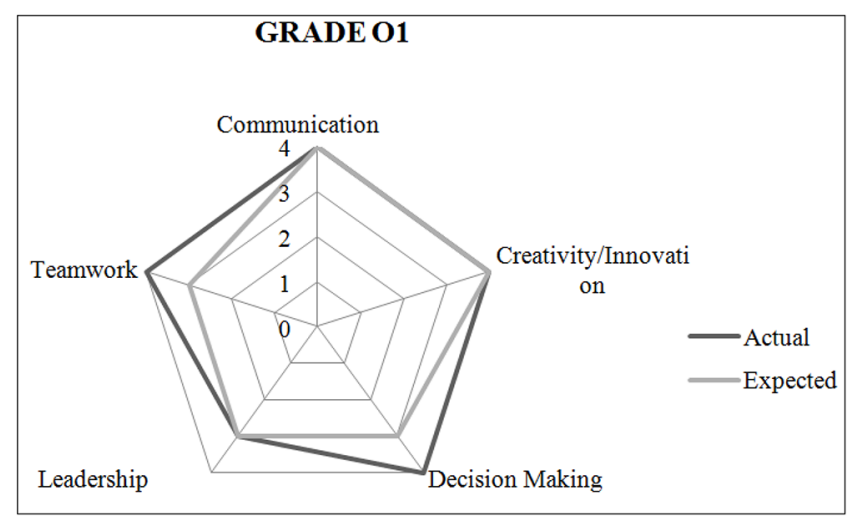

Figure 6. Gap analysis: Grade $\mathrm{O} 1$.

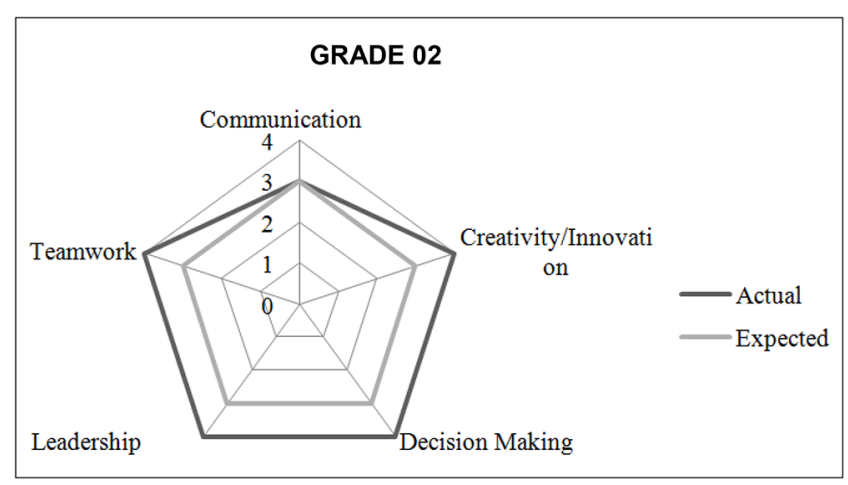

Figure 7. Gap analysis: Grade $\mathrm{O} 2$.

the expected level for decision making and teamwork skills among Grade 01 (Figure 6). It is assessed that the employees meet the expectation of communication skill and exceeded the expected level for decision making, creativity/innovation, and leadership and teamwork skills among Grade 02 (Figure 7).

\section{The Mean Score of the Defined Core Competencies}

From the mean score shown in Table 2 it is observed that the communication, decision making and teamwork are

Table 2. Mean score of the core competencies

\begin{tabular}{|l|c|c|}
\hline Competencies & Mean & SD \\
\hline Communication & 3.888 & 0.7284 \\
\hline Creativity/Innovation & 3.2 & 0.7652 \\
\hline Decision Making & 4.028 & 0.7376 \\
\hline Leadership & 3.381 & 0.8724 \\
\hline Teamwork & 4.144 & 0.7752 \\
\hline Overall & $\mathbf{3 . 7 2 8 2}$ & $\mathbf{0 . 7 7 5 7 6}$ \\
\hline
\end{tabular}

post possessed skills and leadership and creativity/innovation skills are least possessed. And the overall mean score, interprets that the respondents are enough competent to do their job.

\section{Correlation between Experience and Core Competency Gap}

\subsection{Hypothesis}

- Null Hypothesis: There is significant relationship between the core competencies and number of years of service, and

- Alternative Hypothesis: There is no significant relationship between the core competencies and number of years of service shown in Table 3. It is interpreted that there is no a significant relationship between experience and communication, creativity/ innovation, decision-making, leadership and teamwork skills.

\section{Identify the Differences in Core Competencies across Employee Grades}

\subsection{Hypothesis}

- Null Hypothesis: There is no significant difference between grades and core competencies, and

- Alternative Hypothesis: There is significant difference between grades and core competencies shown in Table 4. The significance level is greater than 0.05 for all core competencies expected in the study. Therefore, irrespective of the grade the employees possess they own and expose the above core competencies.

Table 3. Correlation between the experience and core competency gap

\begin{tabular}{|l|c|c|c|}
\hline \multirow{2}{*}{} & \multicolumn{3}{|c|}{ Experience } \\
\cline { 2 - 4 } & $\begin{array}{c}\text { Pearson } \\
\text { Correlation }\end{array}$ & $\begin{array}{c}\text { Sig. } \\
\text { (2-tailed) }\end{array}$ & $\mathrm{N}$ \\
\hline Communication & .127 & .379 & 50 \\
\hline Creativity/Innovation & .106 & .464 & 50 \\
\hline Decision Making & .107 & .460 & 50 \\
\hline Leadership & -.130 & .369 & 50 \\
\hline Teamwork & .153 & .288 & 50 \\
\hline
\end{tabular}


Table 4. One way ANOVA for each core competency across employee grades

\begin{tabular}{|c|c|c|c|c|c|c|}
\hline & & Sum of Squares & df & Mean Square & $\mathrm{F}$ & Sig. \\
\hline \multirow[t]{3}{*}{ Communication } & Between Groups & 4.394 & 6 & .732 & 2.183 & .063 \\
\hline & Within Groups & 14.426 & 43 & .335 & & \\
\hline & Total & 18.820 & 49 & & & \\
\hline \multirow[t]{3}{*}{ Creativity/Innovation } & Between Groups & 4.416 & 6 & .736 & 1.241 & .305 \\
\hline & Within Groups & 25.504 & 43 & .593 & & \\
\hline & Total & 29.920 & 49 & & & \\
\hline \multirow[t]{3}{*}{ Decision Making } & Between Groups & 2.642 & 6 & .440 & .867 & .527 \\
\hline & Within Groups & 21.838 & 43 & .508 & & \\
\hline & Total & 24.480 & 49 & & & \\
\hline \multirow[t]{3}{*}{ Leadership } & Between Groups & .977 & 6 & .163 & .399 & .875 \\
\hline & Within Groups & 17.523 & 43 & .408 & & \\
\hline & Total & 18.500 & 49 & & & \\
\hline \multirow[t]{3}{*}{ Teamwork } & Between Groups & 2.199 & 6 & .366 & .588 & .738 \\
\hline & Within Groups & 26.781 & 43 & .623 & & \\
\hline & Total & 28.980 & 49 & & & \\
\hline
\end{tabular}

\section{Findings}

1. Employees were normal and neutral in giving opinion to their respective leaders and the leadership qualities and creativity/innovation skills,

2. The overall mean score showcases that the employees are competent enough in taking their assigned job in their specialized area,

3. There is no positive relationship between core competencies and experience,

4. There is no significant difference between the core competencies and grades of the employees,

5. Communication, decision making and teamwork are most possessed and preferred core competencies and leadership and creativity/innovation are least possessed core competencies in the MSME sector,

6. SM4 employees own the expectation and are getting mapped with communication skill,

7. M4 employees meet out the expectation of teamwork and decision making skills of employees,

8. M3 employees meet the expectation for creativity and teamwork skills, communication in maximum levels,

9. M2 employees meet the expectation for teamwork and decision making skills,

10. M1 employees meet communication, creativity and leadership skills up to the expected levels,

11. O1 group meets the expectation for creativity/innovation and leadership skills, communication, and
12. O2 group meets the expectation for communication skill in their expected levels.

\section{Suggestions}

From the above research study it is analyzed that the data of the employees identified for the study have medium level of core competencies in creativity/innovation and leadership skills. Therefore, the MSME sector can bring and implement a culture of open and ongoing communication that will suit all the levels. The leadership skills of employees in industry can be developed through motivation and encouragement with intrinsic and motivational factors. This will assist them to participate in personality development programs, Simulation training conducted within and outside the industry by related industries. MSME sector is one of the contributing sectors for the nation, which has a higher influence in increasing the GDP of the nation. It is suggested to show improvement and insists developments in the grey areas identified in this research study.

\section{Conclusion}

Communication, creativity/innovation, decision making, leadership and teamwork are the five identified core competencies to run an industry successfully. When employee 
own the expected and defined competencies their efficiency and effectiveness moves in the positive direction with reference to production and related business activities. From the mathematical analysis it is inferred that any job without core competency definition will be a failure model. When a job is designed it should have a competency mapping. This will be a benchmarked framework for employees to take their respective roles with accountability and responsibility in any industry. Talent management and Core competency mapping are highly essential to maximize the utilization of any employees' talents to gain competitive advantage in an industry is proved by the stated mathematical model.

\section{Reference}

1. The Inclusive growth and development report. World Economic Forum; 2017. p. 1-75.

2. Madan C. Competency Mapping at 'The Kolkata Glory’. IBS Case Development Center; 2009. p. 1-19.
3. Chaudhary S, Singh S. A study of competency mapping of employees in banking sector, International Journal of Human Resources Management. 2016; 5(3):11-20.

4. Sarkar S. Competency based training need assessment Approach in Indian companies, Journal of Management, Informatics and Human Resource. 2013; 46(6):1-11.

5. Soundara Rajan LJ, Ananda Kumar A. Competency mapping analysis: A study conducted in specific package industry at Puducherry State of Indian, European Journal of Business and Management. 2015; 7(19):1-12.

6. Yuvaraj R. Competency mapping- A driver for Indian Industries, International Journal of Scientific and Engineering Research. 2011; 2(8):1-7.

7. Murtaza Z. An empirical study of competency mapping of the employees in the tourism sector in Jammu and Kashmir An executive level perspective, Journal of Business Management and Social Sciences Research. 2015; 4(2):1-7. 